\title{
Faktor-Faktor yang Mempengaruhi Struktur Modal Perusahaan Batubara Periode 2010-2019
}

\author{
Nabilah Putri Syabana ${ }^{\varpi 1}$, Tieka Trikartika Gustyana² \\ 1,2 Manajemen Bisnis Telekomunikasi dan Informatika, Fakultas Ekonomi dan Bisnis, Universitas Telkom
}

\begin{abstract}
ABSTRAK
Hasil penelitian ini mengungkapkan bahwa variabel profitabilitas, likuiditas, struktur aset, ukuran perusahaan dan pertumbuhan penjualan berpengaruh signifikan terhadap struktur modal. Variabel profitabilitas berpengaruh negatif signifikan terhadap struktur modal, sedangkan variabel struktur aset dan ukuran perusahaan berpengaruh positif signifikan terhadap struktur modal, dan variabel likuiditas dan pertumbuhan penujualan tidak berpengaruh terhadap struktur modal. Berdasarkan hasil penelitian, pihak investor disarankan untuk berinvestasi pada perusahaan yang memiliki ukuran besar, struktur aset yang besar dan lebih memperhatikan perusahaan yang memiliki profitabilitas yang rendah agar dapat memperoleh struktur modal yang optimal dan menghasilkan keuntungan yang maksimal. Pihak perusahaan disarankan untuk meningkatkan profitabilitas jika ingin menurunkan proporsi struktur modal, meningkatkan struktur aset dan meningkatkan ukuran perusahaan jika ingin menarik minat investor untuk menanamkan modal pada perusahaan.
\end{abstract}

Kata-kunci: Struktur Modal, Profitabilitas, Likuiditas, Struktur Aset, Ukuran Perusahaan dan Pertumbuhan Penjualan

\begin{abstract}
The results of this study reveal that the variables of profitability, liquidity, asset structure, company size and sales growth have a significant effect on capital structure. Profitability variables have a significant negative effect on capital structure, while the variables of asset structure and firm size have a significant positive effect on capital structure, and the variables of liquidity and sales growth have no effect on capital structure. Based on the research results, investors are advised to invest in companies that have large sizes, large asset structures and pay more attention to companies that have low profitability in order to obtain optimal capital structures and generate maximum profits. The company is advised to increase profitability if you want to reduce the proportion of the capital structure, increase the asset structure and increase the size of the company if you want to attract investors to invest in the company.
\end{abstract}

Keywords : Capital Structure, Profitability, Liquidity, Asset Structure, Company Size and Sales Growth

$\triangle$ Corresponding author :

Email Address : nabilahutri@telkomuniversity.ac.id

"Received 12, Januari 2020, Accepted 15, Februari 2021, Published 06, Mei 2021" 


\section{Pendahuluan}

Persaingan usaha antar perusahaan sangatlah ketat pada era globalisasi saat ini. Perusahaan dituntut agar mampu memaksimalkan nilai perusahaan agar mampu bersaing dengan perusahaan lain (Febriani \& Kristani 2020). Menurut Hadiprajitno (2014) optimalisasi nilai perusahaan merupakan tujuan penting yang harus dicapai perusahaan, salah satunya dengan pelaksanaan fungsi manajemen keuangan, keputusan keuangan yang diambil akan mempengaruhi kinerja keuangan perusahaan dan berdampak pada nilai perusahaan. Nilai perusahaan yang optimal akan menjadikan perusahaan tersebut memiliki kinerja yang baik. Salah satu jenis keputusan keuangan adalah keputusan pendanaan, yaitu merupakan pemilihan sumber dana yang digunakan untuk melakukan aktivitas operasi perusahaan. Keputusan pendanaan adalah manajer keuangan harus dapat memutuskan apakah akan mengumpulkan dana dari menjual lebih banyak saham atau dengan meminjam dana atau hutang. Keputusan pendanaan juga disebut sebagai struktur modal. Struktur modal merupakan salah satu faktor fundamental operasi.

Penelitian ini menggunakan subsektor batubara sebagai objek penelitian karena merupakan salah satu sektor industri yang besar di Indonesia dengan tingkat ekspor yang tinggi dan membutuhkan modal yang besar agar dapat diminati oleh para investor (Fatoni et al, 2013). Sektor pertambangan menyumbangkan 5-8\% dari PDB Indonesia dalam sepuluh tahun terakhir, yang 80\%-nya berasal dari sub sektor batubara. Tahun 2018, pemerintah meningkatkan produksi batu bara hingga lebih dari 500 juta ton dan membuat penambang dapat mengekspor lebih banyak batu bara untuk meningkatkan pendapatan ekspor dan membantu menyeimbangkan defisit yang berasal dari perdagangan minyak dan gas.

Dalam permodalan, perusahaan besar yang memiliki stabilitas penjualan yang baik, profitabilitas yang tinggi dan tingkat pertumbuhan yang tinggi tidak akan begitu tergantung dana dengan pihak luar. Perusahaan yang memiliki prospek baik memiliki sumber dana dari dalam berupa laba yang cukup besar yang dapat digunakan untuk mencukupi modal usaha mereka. Hal ini sejalan dengan konsep dalam Pecking Order Theory, teori yang dikembangkan oleh Stewart Myers pada tahun 1984, mengatakan bahwa perusahaan mengutamakan pendanaan dari sumber internal daripada pendanaan yang bersumber dari eksternal perusahaan.

Struktur modal berhubungan dengan nilai perusahaan. Semakin tinggi nilai utang dalam suatu perusahaan atau semakin tinggi risiko yang dimiliki oleh perusahaan, maka nilai perusahaan akan semakin meningkat karena cost of debt yang lebih rendah dibandingkan dengan cost of capital. Oleh karena itu, agar kondisi tersebut dapat tercapai maka perlu pertimbangan variabel-variabel yang mempengaruhi struktur modal. Dalam penelitian ini, penulis menggunakan beberapa variabel yang dapat mempengaruhi struktur modal yaitu 
(a) profitabilitas, (b) likuiditas, (c) struktur aset, (d) ukuran perusahaan, dan (e) pertumbuhan penjualan.

\section{Kajian Literatur}

Struktur Modal

Menurut Keown et al, (2017:445) istilah struktur modal merujuk pada bagaimana cara perusahaan mendanai asetnya menggunakan kombinasi antara hutang dan ekuitas. struktur modal perusahaan harus melakukan perencanaan dengan baik struktur permodalan perusahaan karena apabila struktur modal tidak direncanakan dengan baik perusahaan hanya akan bertahan dalam waktu yang singkat dan mungkin perusahaan akan menghadapi kesulitan yang cukup besar dalam mengumpulkan dana untuk membiayai kegiatan operasi perusahaan mereka.

\section{Profitabilitas}

$$
\mathrm{DER}=\frac{\text { Total Liabilitas }}{\text { Total Ekuitas }}
$$

Pandey (2015:593-594) menjelaskan bahwa rasio profitabilitas merupakan perusahaan harus mendapatkan keuntungan untuk bertahan dan tumbuh dalam jangka waktu yang lama. Keuntungan dinilai sangat penting untuk dapat mengukur kinerja suatu perusahaan. . Profitabilitas merupakan output utama perusahaan dan perusahaan tidak akan memiliki masa depan apabila gagal dalam menghasilkan keuntungan yang cukup. Oleh karena itu, pengelola keuangan harus terus melakukan evaluasi efesiensi perusahaan dalam hal profitabilitas.

\section{Likuiditas}

$$
R \mathrm{OA}=\frac{\text { Laba Bersih }}{\text { Total Aset }}
$$

Pandey (2015:584) menjelaskan bahwa likuiditas mengukur kemampuan perusahaan untuk memenuhi kewajiban yang dimiliki oleh perusahaan saat ini. Sangat penting bagi perusahaan untuk memenuhi kewajibannya karena apabila perusahaan gagal untuk memenuhi kewajibannya karena kurangnya likuiditas yang cukup akan mengakibatkan kebangkrutan dalam perusahaan.

$$
\mathrm{CR}=\frac{\text { Aset Lancar }}{\text { Hutang Lancar }}
$$

\section{Struktur Aset}

Betavia (2019) menjelaskan bahwa dalam menjalankan aktivitas operasinya, perusahaan memberikan segala aset berupa sumber daya dan harta yang dimilikinya. Pada umumnya perusahaan memiliki dua jenis aset yaitu aset tetap dan aset lancar. Kedua jenis aset ini akan membentuk struktur aset. Struktur aset juga biasa disebut struktur aktiva atau struktur kekayaan perusahaan. Struktur aset memberikan gambaran sebagian besar jumlah aset yang dimiliki oleh perusahaan dapat dijadikan sebagai jaminan hutang perusahaan. 


$$
\text { Fixed Asset Ratio }=\frac{\text { Aset Tetap }}{\text { Total Aset }}
$$

\section{Ukuran Perusahaan}

Alnajjar (2015) dalam penelitiannya mengatakan bahwa ukuran perusahaan memiliki hubungan yang bervariasi dengan pembiayaan hutang jangka pendek dan hutang jangka panjang. Studi Marsh tahun 1982 mengatakan bahwa perusahaan dengan ukuran yang besar lebih menyukai menggunakan hutang dengan jangka panjang, sedangkan perusahaan yang lebih kecil lebih menyukai menggunakan hutang jangka pendek.

$$
\text { Ukuran Perusahaan=Ln (Total Aset) }
$$

\section{Pertumbuhan Penjualan}

Menurut Betavia (2019), pertumbuhan penjualan atau growth merupakan gambaran dari proses produktivitas perusahaan. Pertumbuhan penjualan juga dinilai penting bagi pihak internal perusahaan dan juga eksternal perusahaan. Pertumbuhan menjadi indikator berkembang atau tidaknya perusahaan.

$$
\text { Pertumbuhan Penjualan }=\frac{\text { Penjualan }_{t}-\text { Penjualan }_{t-1}}{\text { Penjualan }_{t-1}}
$$

\section{Kerangka Pemikiran}

Gambar 2.1 Kerangka Pemikiran

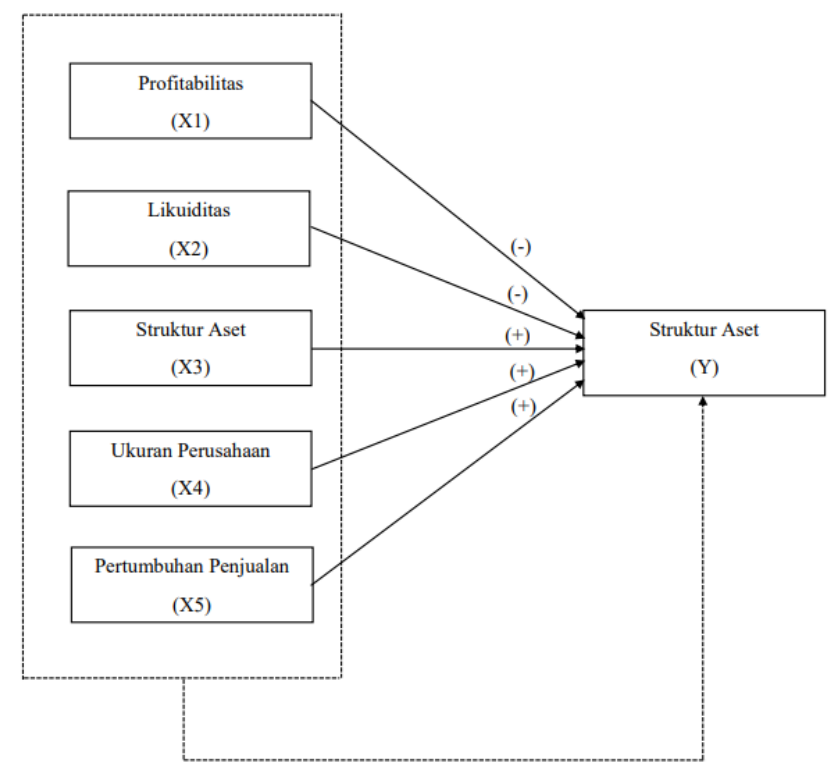




\section{Hipotesis Penelitian}

H1 : Profitabilitas, Likuiditas, Struktur Aset, Ukuran Perusahaan, dan Pertumbuhan penjualan berpengaruh secara stimulan terhadap Struktur Modal pada Perusahaan Subsektor Batubara yang terdaftar di BEI Periode 2010-2019

H2 : Profitabilitas berpengaruh negatif dan signifikan terhadap Struktur Modal pada Perusahaan Subsektor Batubara yang terdaftar di BEI Periode 2010-2019

H3 : Likuiditas berpengaruh negatif dan signifikan terhadap Struktur Modal pada Perusahaan Subsektor Batubara yang terdaftar di BEI Periode 2010-2019

H4 : Struktur Aset berpengaruh positif dan signifikan terhadap Struktur Modal pada Perusahaan Subsektor Batubara yang terdaftar di BEI Periode 2010-2019

H5 : Ukuran Perusahaan berpengaruh positif dan signifikan terhadap Struktur Modal pada Perusahaan Subsektor Batubara yang terdaftar di BEI Periode 2010-2019

H6 : Pertumbuhan Penjualan berpengaruh positif dan signifikan terhadap Struktur Modal pada Perusahaan Subsektor Batubara yang terdaftar di BEI Periode 20102019

\section{Metode Penelitian}

Metode yang digunakan dalam penelitian ini adalah analisis regresi data panel dengan menggunakan analisis statistik deskriptif. Populasi yang digunakan adalah perusahaan subsektor batubara yang terdaftar di Bursa Efek Indonesia (BEI) periode 2010-2019 dengan menggunakan teknik non-probability sampling dan memiliki kriteria yaitu : (1) Perusahaan pertambangan sub sektor batu bara yang sudah dan masih terdaftar di Bursa Efek Indonesia periode 2010-2019, (2) Perusahaan pertambangan sub sektor batu bara yang konsisten mempublikasikan laporan keuangannya melalui website resmi perusahaan atau website Bursa Efek Indonesia periode 2010-2019. Data yang diperoleh sebanyak 120 terdiri dari 12 perusahaan dengan periode penelitian selama 10 tahun.

Metode analisis yang digunakan dalam penelitian ini adalah analisis regresi data panel yang persamaannya dituliskan sebagai berikut:

$$
Y=\alpha+\beta \_1 X \_1 i t+\beta \_2 X \_2 i t+\beta \_3 X \_3 i t+\beta \_4 X \_4 i t+\beta \_5 \text { X_5+e_it }
$$

Dimana :

\begin{tabular}{|c|c|c|c|}
\hline Y & = Variabel Dependen & $X \_4$ & $=$ Ukuran Perusahaan \\
\hline$\alpha$ & $=$ Konstanta & X_5 & $=$ Pertumbuhan Penjualan \\
\hline
\end{tabular}




\begin{tabular}{|c|c|c|c|}
\hline$\beta \_1-\beta \_5$ & = Koefisien Regresi & $\mathrm{i}$ & $=$ Entitas \\
\hline X_1 & $=$ Profitabilitas & $\mathrm{t}$ & $=$ Periode \\
\hline X_2 & = Likuiditas & $\mathrm{e}$ & $=$ Error term \\
\hline X 3 & $=$ Struktur Aset & & \\
\hline
\end{tabular}

\title{
4. Hasil Penelitian
}

Analisis Statistik Deskriptif

Tabel 1. Hasil Uji Statistik Deskriptif

\begin{tabular}{lcccccc}
\hline & DER & ROA & CR & FAR & SIZE & SALES \\
\hline Mean & 0,883 & 0,056 & 2,378 & 0,27 & 29,021 & 0,192 \\
\hline Median & 0.655 & 0,048 & 1,715 & 0,253 & 29,276 & 0,071 \\
\hline Maximum & 4,447 & 0,455 & 14,829 & 0,674 & 32,253 & 8,921 \\
\hline Minimum & 0,076 & $(0,661)$ & 0,166 & 0,00 & 23,045 & $(0,871)$ \\
\hline Standar Deviasi & 0,8 & 0,146 & 2,344 & 0,153 & 1,713 & 1,004 \\
\hline Observasi & 120 & 120 & 120 & 120 & 120 & 120 \\
\hline
\end{tabular}

Sumber : Data Diolah Penulis (2021)

Berdasarkan data pada tabel 1, variabel struktur modal (DER), likuiditas (CR), struktur aset (FAR), ukuran perusahaan (SIZE) nilai rata-rata lebih besar dibandingkan dengan nilai standar deviasi sehingga dapat disimpulkan bahwa data pada variabel diatas berkelompok. Sedangkan variabel profitabilitas (ROA) dan pertumbuhan penjualan (SALES) memiliki nilai raya-rata lebih kecil dibandingkan dengan nilai standar deviasi, dapat disimpulkan bahwa data pada variabel tersebut bervariasi.

\section{Pemilihan Model Regresi}

a. Uji Chow

\section{Tabel 2. Hasil Uji Chow}

\author{
Redundant Fixed Effects Tests \\ Equation: Untitled \\ Test cross-section fixed effects
}

\begin{tabular}{lrrr}
\hline \hline Effects Test & Statistic & d.f. & Prob. \\
\hline \hline & & & \\
Cross-section F & 9.239853 & $(11,103)$ & 0.0000 \\
Cross-section Chi-square & 82.381853 & 11 & 0.0000 \\
\hline \hline
\end{tabular}

Sumber : Output Eviews 10 (2021) 
Berdasarkan tabel hasil uji spesifikasi menggunakan uji Chow, dapat dilihat pada nilai probabilitas cross section $\mathrm{F}$ adalah sebesar 0,0000 nilai ini berada dibawah atau < 0,05 yang artinya $\mathrm{H}_{0}$ ditolak dan $\mathrm{H}_{\mathrm{a}}$ diterima. Jadi berdasarkan hasil uji Chow diatas, model regresi data panel fixed effect dianggap lebih baik dibandingkan dengan model common effect. Setelah model regresi data panel fixed effect terpilih, selanjutnya akan dilakukan pengujian Hausman.

b. Uji Hausman

Tabel 3. Hasil Uji Hausman

Correlated Random Effects - Hausman Test

Equation: HAUSMAN_RANDOM

Test cross-section random effects

\begin{tabular}{lrrr}
\hline \hline Test Summary & Chi-Sq. Statistic & Chi-Sq. d.f. & Prob. \\
\hline \hline Cross-section random & 4.920957 & 5 & 0.4256 \\
\hline \hline
\end{tabular}

Berdasarkan tabel hasil uji spesifikasi menggunakan uji Hausman, dapat dilihat pada nilai probabilitas cross section Random adalah sebesar 0,4256 nilai ini berada diatas atau $>0,05$ yang artinya $\mathrm{H}_{0}$ diterima dan $\mathrm{H}_{a}$ ditolak. Jadi berdasarkan hasil uji Hausman diatas, model regresi data panel random effect dianggap lebih baik dibandingkan dengan model fixed effect. Setelah model regresi data panel random effect terpilih, selanjutnya akan dilakukan pengujian Lagrange Multiplier.

c. Uji Lagrange Multiplier

Tabel 4. Hasil Uji Lagrange Multiplier

Lagrange multiplier (LM) test for panel data

Date: 01/10/21 Time: 00:01

Sample: 20102019

Total panel observations: 120

Probability in ()

\begin{tabular}{lccc}
\hline \hline $\begin{array}{l}\text { Null (no rand. effect) } \\
\text { Alternative }\end{array}$ & $\begin{array}{c}\text { Cross-section } \\
\text { One-sided }\end{array}$ & $\begin{array}{c}\text { Period } \\
\text { One-sided }\end{array}$ & Both \\
\hline \hline Breusch-Pagan & 97.93150 & 1.965552 & 99.89705 \\
Honda & $(0.0000)$ & $(0.1609)$ & $(0.0000)$ \\
& 9.896034 & -1.401982 & 6.006202 \\
King-Wu & $(0.0000)$ & $(0.9195)$ & $(0.0000)$ \\
& 9.896034 & -1.401982 & 5.598724 \\
SLM & $(0.0000)$ & $(0.9195)$ & $(0.0000)$ \\
& 12.15841 & -1.250134 & -- \\
GHM & $(0.0000)$ & $(0.8944)$ & -- \\
& -- & -- & 97.93150 \\
\hline \hline
\end{tabular}

Sumber : Output Eviews 10 (2021)

Berdasarkan tabel hasil uji spesifikasi menggunakan uji Lagrange Multiplier, dapat dilihat pada nilai probabilitas Breusch-Pagan adalah sebesar 0,0000 nilai ini berada dibawah atau $<0,05$ yang artinya $\mathrm{H}_{0}$ ditolak dan $\mathrm{H}_{\mathrm{a}}$ diterima. Jadi berdasarkan hasil 
uji Lagrange Multiplier diatas, model regresi data panel random effect dianggap lebih baik dibandingkan dengan model common effect.

\section{Pembahasan}

Analisis Data Panel

Tabel 5. Hasil Analisis Data Panel

Dependent Variable: DER

Method: Panel EGLS (Cross-section random effects)

Date: 01/10/21 Time: 00:26

Sample: 20102019

Periods included: 10

Cross-sections included: 12

Total panel (balanced) observations: 120

Swamy and Arora estimator of component variances

\begin{tabular}{|c|c|c|c|c|}
\hline Variable & Coefficient & Std. Error & t-Statistic & Prob. \\
\hline C & -4.065215 & 2.129897 & -1.908644 & 0.0588 \\
\hline $\mathrm{ROA}$ & -2.262809 & 0.466214 & -4.853581 & 0.0000 \\
\hline $\mathrm{CR}$ & 0.004101 & 0.023919 & 0.171460 & 0.8642 \\
\hline FAC & 1.981718 & 0.592365 & 3.345433 & 0.0011 \\
\hline SIZE & 0.155553 & 0.072816 & 2.136261 & 0.0348 \\
\hline SALES & 0.075936 & 0.052762 & 1.439209 & 0.1528 \\
\hline \multicolumn{5}{|c|}{ Effects Specification } \\
\hline & & & S.D. & Rho \\
\hline Cross-section random & & & 0.501530 & 0.4765 \\
\hline Idiosyncratic random & & & 0.525684 & 0.5235 \\
\hline \multicolumn{5}{|c|}{ Weighted Statistics } \\
\hline R-squared & 0.268999 & \multicolumn{2}{|c|}{ Mean dependent var } & 0.277933 \\
\hline Adjusted R-squared & 0.236938 & \multicolumn{2}{|c|}{ S.D. dependent var } & 0.601581 \\
\hline S.E. of regression & 0.525501 & \multicolumn{2}{|c|}{ Sum squared resid } & 31.48128 \\
\hline F-statistic & 8.390124 & \multicolumn{2}{|c|}{ Durbin-Watson stat } & 1.153215 \\
\hline Prob(F-statistic) & 0.000001 & & & \\
\hline
\end{tabular}

Sumber : Output Eviews 10 (2021)

a. Uji Koefisien Determinasi

Hasil pengujian disajikan dalam tabel 5. Hasil uji koefisien determinasi menemukan bahwa nilai adjusted R-squared menunjukkan hasil 0,236938 atau 23,6938\%. Dengan demikian dapat diketahui bahwa variabel independen dapat menjelaskan variabel dependen adalah sebesar 0,236938 atau 23,6938\%.

b. Uji Hipotesis Simultan

Berdasarkan hasil uji F atau uji simultan nilai Prob (F-statistic) adalah sebesar 0,00001 yang memiliki nilai lebih kecil dari nilai signifikansi atau <0,05. Maka dapat disimpulkan bahwa variabel independen profitabilitas (ROA), likuiditas (CR), 
struktur aset (FAR), ukuran perusahaan (SIZE) dan pertumbuhan penjualan (SIZE) secara simultan berpemgaruh signifikan terhadap struktur modal (DER).

c. Uji Hipotesis Parsial

\section{Pengaruh Profitabilitas terhadap Struktur Modal}

Hasil pengujian secara parsial seperti pada tabel 5 menunjukkan bahwa profitabilitas memiliki nilai probabilitas (p-value) 0,0000 yaitu < atau lebih kecil dari 0,05 . Maka hal ini menunjukkan bahwa variabel profitabilitas memiliki pengaruh terhadap struktur modal, sehingga besar dan kecilnya laba atau rugi yang diperoleh oleh perusahaan akan merubah nilai dari struktur modal. Adapun nilai koefisien yang dimiliki oleh variabel profitabilitas adalah $-2,262809$, maka profitabilitas memiliki arah negatif yang menunjukkan adanya pengaruh yang bertolak belakang terhadap struktur modal. Sehingga dapat disimpulkan bahwa profitabilitas (ROA) berpengaruh negatif signifikan terhadap struktur modal (DER).

\section{Pengaruh Likuiditas terhadap Struktur Modal}

Hasil pengujian secara parsial seperti pada tabel 5 menunjukkan bahwa likuiditas memiliki nilai probabilitas ( $p$-value) 0,8642 yaitu $>$ atau lebih besar dari 0,05 . Maka hal ini menunjukkan bahwa variabel likuiditas tidak memiliki pengaruh terhadap struktur modal, sehingga besar dan kecilnya kemampuan perusahaan dalam melunasi utang lancar dan aset lancar yang dimiliki oleh perusahaan tidak akan berpengaruh pada nilai struktur modal. Adapun nilai koefisien yang dimiliki oleh variabel likuiditas adalah 0,004101. Sehingga dapat disimpulkan bahwa likuiditas (CR) tidak berpengaruh signifikan terhadap struktur modal (DER)

\section{Pengaruh Struktur Aset terhadap Struktur Modal}

Hasil pengujian secara parsial seperti pada tabel 5 menunjukkan bahwa sruktur aset memiliki nilai probabilitas (p-value) 0,0011 yaitu < atau lebih kecil dari 0,05. Maka hal ini menunjukkan bahwa variabel struktur aset memiliki pengaruh terhadap struktur modal, sehingga besar dan kecilnya struktur aset yang dimiliki oleh perusahaan akan merubah nilai dari struktur modal. Adapun nilai koefisien yang dimiliki oleh variabel struktur aset adalah 1,981718 maka struktur aset memiliki arah positif yang menunjukkan adanya pengaruh yang sejalan terhadap struktur modal. Dengan demikian semakin besar nilai struktur aset perusahaan maka akan semakin besar pula struktur modal perusahaan.

\section{Pengaruh Ukuran Perusahaan terhadap Struktur Modal}

Hasil pengujian secara parsial seperti pada tabel 5 menunjukkan bahwa ukuran perusahaan memiliki nilai probabilitas (p-value) 0,0348 yaitu < atau lebih kecil dari 0,05. Maka hal ini menunjukkan bahwa variabel ukuran perusahaan memiliki pengaruh terhadap struktur modal, sehingga besar dan kecilnya ukuran suatu perusahaan akan merubah nilai struktur modal. Adapun nilai koefisien yang dimiliki oleh variabel struktur aset adalah 0,155553 maka ukuran perusahaan memiliki arah positif yang menunjukkan adanya pengaruh yang sejalan terhadap struktur modal (DER). 


\section{Pengaruh Pertumbuhan Penjualan terhadap Struktur Modal}

Hasil pengujian secara parsial seperti pada tabel 5 menunjukkan bahwa pertumbuhan penjualan memiliki nilai probabilitas (p-value) 0,1528 yaitu $>$ atau lebih besar dari 0,05. Maka hal ini menunjukkan bahwa variabel pertumbuhan penjualan tidak memiliki pengaruh terhadap struktur modal, sehingga besar dan kecilnya pertumbuhan penjualan yang dialami oleh perusahaan tidak akan berpengaruh pada nilai struktur modal. Adapun nilai koefisien yang dimiliki oleh variabel pertumbuhan penjualan adalah 0,0759936. Sehingga dapat disimpulkan bahwa pertumbuhan penjualan (SALES) tidak berpengaruh signifikan terhadap struktur modal (DER).

\section{Kesimpulan}

Secara simultan dapat disimpulkan bahwa variabel independen profitabilitas (ROA), likuiditas (CR), struktur aset (FAR), ukuran perusahaan (SIZE) dan pertumbuhan penjualan (SIZE) secara simultan berpemgaruh signifikan terhadap struktur modal (DER). Secara parsial dapat disimpulkan sebagai berikut :

a. Variabel profitabilitas berpengaruh negatif signifikan terhadap variabel struktur modal.

b. Variabel struktur aset dan ukuran perusahaan berpengaruh positif signifikan terhadap variabel struktur modal.

c. Variabel likuiditas dan pertumbuhan penjualan tidak berpengaruh terhadap variabel struktur modal.

\section{Referensi :}

Acaravci, S. K. (2015). The Determinants of Capital Structure : Evidence from the Turkish Manufacturing Sector. International Journal of Economics and Financial Issues Vol. 5, No. 1, 158-171Alnajjar, M. I. (2015). Business Risk Impact on Capital Structure: A Case of Jordan Industrial Sector. Global Journal of Management and Business Research: $C$ Finance, 1-8.

Berk, J., \& DeMarzo, P. (2017). Corporate Finance, 4th Edition. Stanford, United States: Pearson.

Betavia, A. E. (2019). Analisis Pengaruh Profitabilitas, Likuiditas, Kebijakan Dividen, Pertumbuhan Perusahaan dan Struktur Aktiva Terhadap Struktur Modal. Jurnal Eksplorasi Akuntansi Vol. 1, No 4, Seri B,, 1741-1755.

Cevheroglu-Acar, M. G. (2018). Determinants of Capital Structure: Empirical Evidence from Turkey. Journal of Management and Sustainability; Vol. 8, No. 1; 31-45.

Febriani, A. D., \& Kristanti, F. T. (2020). Determinan Struktur Modal Perusahaan Infrastruktur, Utilitas dan Transportasi. E-Jurnal Ekonomi dan Bisnis Universitas Udayana 9.3 (2020), 275-302. 
Firmanullah, N., \& Darsono. (2017). Faktor-faktor yang Mempengaruhi Struktur Modal di Perusahaan Indonesia (Pada Perusahaan Manufaktur yang Terdaftar di BEI Tahun 2011-2014). Diponegoro Journal of Accounting Volume 6, Nomor 3, 1-9.

Keown, A. J., Martin, J. D., \& Petty, W. J. (2017). Foundations of Finance Ninth Edition. Boston: Pearson Education Limited.

Liang, I., \& Natsir, K. (2019). Pengaruh Profitabilitas, Likuiditas Dan Ukuran Perusahaan Terhadap Struktur Modal. Jurnal Manajerial dan Kewirausahaan, Volume I No. 3, 481480.

Mulyawan, S. (2015). Manajemen Keuangan. Bandung : CV PUSTAKA SETIA

Pandey, I. M. (2015). Financial Management 11th Edition. New Delhi: Vikas Publishing House PVT LTD.

Permatasari, M. (2019). Pengaruh Ukuran Perusahaan, Profitabilitas, Struktur Aset, Pertumbuhan Penjualan dan Likuiditas Terhadap Struktur Modal . Jurnal Riset Mahasiswa Akuntansi Volume 7, 1-9.

Sudana, I. M. (2019). Manajemen Keuangan Perusahaan. Jakarta: Erlangga.

Titman, S., Keown, A. J., \& Martin, J. D. (2018). Financial Management Principle and Applications. United Kingdom: Pearson Education Limited.

Wardita, W., \& Astakoni, M. P. (2018). Profitabilitas, Pertumbuhan Perusahaan dan Ukuran Perusahaan Sebagai Determinan Struktur Modal. Kumpulan Riset Akuntansi (Krisna), 20-32. 